\begin{tabular}{|c|c|}
\hline Title & $\begin{array}{l}\text { Formation of bismuth-core carbon-shell nanoparticles by bismuth immersion during plasma CVD synthesis of thin } \\
\text { diamond films }\end{array}$ \\
\hline Author(s) & Takahiro, Tamura; Takuya, Takami; Sachiko, Kobay ashi; Taro, Nagahama; Takashi, Y anase; Toshihiro, Shimada \\
\hline Citation & $\begin{array}{l}\text { Diamond \& Related Materials, 69, 127-132 } \\
\text { https://doi.org/10.1016//.diamond.2016.07.015 }\end{array}$ \\
\hline Issue Date & $2016-10$ \\
\hline Doc URL & http:/hdl.handle.net/2115/71555 \\
\hline Rights & $\begin{array}{l}\text { (0) 2016. This manuscript version is made available under the CC-BY-NC-ND } 4.0 \text { license } \\
\text { http://creativecommons.org/icenses/by-nc-nd/4.0/ }\end{array}$ \\
\hline Rights(URL) & http://creativecommons.org/icenses/by-nc-nd/4.0/ \\
\hline Type & article (author version) \\
\hline File Information & Shimada DRM69(127-132).pdf \\
\hline
\end{tabular}

Instructions for use 


\section{Formation of bismuth-core-carbon-shell nanoparticles by bismuth immersion during plasma CVD synthesis of thin diamond films}

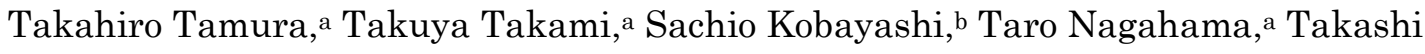
Yanase, ${ }^{\mathrm{a}}$ and Toshihiro Shimada ${ }^{\mathrm{a}, \mathrm{c}}$

a. Division of Applied Chemistry, Faculty of Engineering, Hokkaido University, Kita 13 Nishi 8, Kita-ku, Sapporo 060-8628, Japan.

b. Isotope Imaging Laboratory, Creative Research Institution (CRIS), Hokkaido

University, Kita 21 Nishi 10, Kita-ku, Sapporo 001-0021, Japan.

c. CREST-JST,4-5-3 Yonbancho, Chiyoda-ku, Tokyo 102-8666, Japan

This paper describes an attempt to synthesize bismuth-doped diamond by plasma CVD. Solid bismuth was inserted into the reaction plasma of $\mathrm{CH}_{4}$ and $\mathrm{H}_{2}$. Examination by TEM showed that most of the bismuth was included as Bi nanoparticles in the carbon nanospheres, which segregated at the grain boundary of the diamond polycrystals. Diffraction peaks corresponding to the carbon allotrope Chaoite were observed at the grain boundaries. The Raman spectra showed very complex features between 100-1600 $\mathrm{cm}^{-1}$, suggesting the existance of molecule-like species.

\section{Highlights}

- Synthesis of bismuth-doped diamond by plasma CVD was attempted by solid source immersion technique.

- The obtained sample contained nanoparticle aggregates at grain boundaries of diamond polycrystals.

- The nanoparicles have a core-shell structure containing bismuth as the core.

- Diffraction peaks corresponding to a carbon allotrope Chaoite were observed at the grain boundaries. 


\section{Introduction}

There are various carbon materials; i.e., graphene, carbon nanotube, fullerene, diamond, etc. The variation is still increasing with the addition of less-common allotropes including chaoite[1-2], carbyne[3], compressed super hard graphite[4], m-carbon[5], bct-C4 ${ }_{4}[6], \mathrm{z}^{-}$carbon[7], which are experimentally identified or theoretically predicted. The condition of their formation and physical and chemical properties of them are not fully understood. This paper reports the formation of unusual carbon-containing solid during attempts to synthesize bismuth-doped diamond by plasma CVD.

Doped diamonds are attractive for various exceptional applications [8-11], but it is extremely difficult except for a very few number of elements, such as B, N and P. Since the efficient dopants and their combinations are still being developed for various applications, a simple and versatile technique for the doping of diamond is needed. We here present an attempt to dope bismuth in diamond. If the bismuth doping becomes possible, a good n-type diamond semiconductor might be obtained because the binding energy of the outmost electron decreases as the element size increases. However, this relation does not hold true for P and As in diamond[12]. Clarifying this issue is important for the semiconductor application of diamond. Even if the doping of bismuth to the diamond lattice is impossible, the composite material between bismuth and diamond may be useful because of the catalytic function of $\mathrm{CO}_{2}$ reduction and electrochemical metal sensing ability of bismuth[13,14] combined with electrochemical functions of boron-doped diamond[15].

Popular methods for the doping of the diamond are as follows: (1) using gaseous compounds of dopants [16], or (2) ion implantation followed by annealing [17]. Method (1) has a problem of using toxic gases, whereas method (2) has the problem of a low throughput. We developed a simple and versatile method to supply foreign elements during the plasma CVD, i.e., the solid source immersion in the plasma for the diamond CVD[18], which is similar to the method developed by Kohn et al. for delta-doping[19]. This method has an advantage of supplying various elements with a high concentration without the problems stated above. We examined the films by XRD, XRF, Raman spectroscopy, isotope microscopy and TEM. 


\section{Experimental}

\subsection{Apparatus}

We used compact microwave plasma CVD equipment which uses a microwave antenna as the sample holder (ARIOS DCVD-51A-SSP). A movable rod was vertically attached to this equipment to immerse the solid source (Fig.1 (a)).

(a)

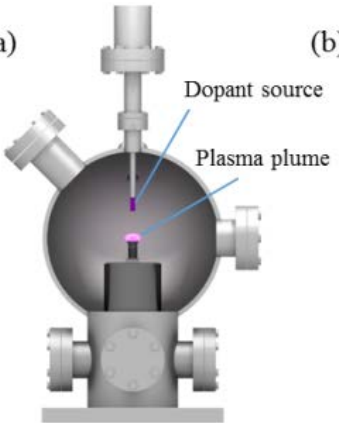

(b)

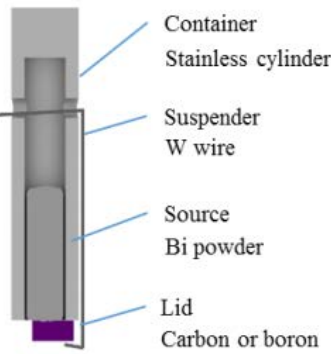

(c)

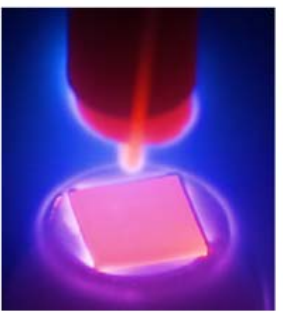

Fig.1.(a) Cross sectional drawing of MPCVD chamber with solid state dopant immersion. (b) Cross sectional drawing of the bismuth container attached to the end of a movable rod. (c) Optical image of the sample and rod during the CVD growth.

The materials we used as substrates were Si substrates ((100) orientation, $5 \times 5 \mathrm{~mm})$, single crystal diamond substrates $((100)$ oriented, $2.5 \times 2.5 \mathrm{~mm})$ and Mo grids for the TEM analysis. The Si substrates were cleaned by the RCA method and scratched by nano-diamond powder in ethanol in an ultrasonic bath for nucleation. The single crystal diamond substrate was cleaned by an $\mathrm{H}_{2}$ plasma. The Mo grids were pretreated by the bias enhanced nucleation (BEN) method [20]. The MW power, total pressure, gas ratio and bias voltage were maintained at $200 \mathrm{~W}, 3000 \mathrm{~Pa}, \mathrm{CH}_{4} / \mathrm{H}_{2}=10 \%$ and $-200 \mathrm{~V}$, respectively. The BEN treatment time was 30 minutes. The substrate holder was made of graphite, because there is a report on abnormal diamond grain growth using a Mo substrate holder [21], and the graphite is easily machined to the designed shape. A specially designed apparatus for immersing the bismuth was attached to the end of the movable rod. Figure 1 (b) shows the cross section of this apparatus. The bismuth container was a cylinder made of stainless steel $(\varphi 4 \mathrm{~mm} \times 25 \mathrm{~mm})$. The open end of this cylinder is covered by a lid made of carbon and $\mathrm{W}$ wire. By using this apparatus, we can supply bismuth to the plasma in a stable manner for a long time ( $\sim 24 \mathrm{~h})$ without dropping as a liquid. Bismuth is an element of a low melting point $\left(271.4^{\circ} \mathrm{C}\right)$ and it melts by the plasma heat and is released from the opening between the reservoir and the lid like ink from a fountain pen. The distance between the bismuth source and the plasma ball is variable, and we have established a calibration procedure to obtain stable results about the bismuth concentration. Figure 1 (c) shows the optical image of the sample and inserted rod in plasma. The blue light emission corresponding to $\mathrm{Bi}$ (472.25 nm, $\left.{ }^{2} \mathrm{D}_{3 / 2} \rightarrow{ }^{3} \mathrm{P}_{1 / 2}\right)$ indicates evaporation of the bismuth [22]. It shows that we can constantly supply $\mathrm{Bi}$ at a high concentration. The flow rates of the source gases $\left(\mathrm{H}_{2}\right.$ and $\left.\mathrm{CH}_{4}\right)$ were electronically regulated by mass flow controllers. The substrate was heated by microwaves and its temperature was measured by a radiation thermometer. The typical temperature was $1050^{\circ} \mathrm{C}$. 


\subsection{Growth conditions}

We initially grew intrinsic poly-crystalline diamond films on the Si substrate to prevent a possible reaction of $\mathrm{Bi}$ with $\mathrm{Si}(\sim 15 \mu \mathrm{m}$ thick). We then inserted the bismuth source into the plasma and applied several bias voltage patterns to the substrate. The growth conditions of the intrinsic diamond CVD were optimized to quickly grow the diamond with a good crystallinity. The growth rate was 0.8 $\mu \mathrm{m} / \mathrm{h}$. The detailed growth conditions and sample descriptions are summarized in Tables 1 and 2, respectively. The applied bias voltage was changed to determine how the bismuth was included in the films. No bias was applied in condition (a). Positive bias was constantly applied in condition (b). A negative bias was constantly applied in condition (c). An alternating bias was used in condition (d).

Table 1. The CVD growth conditions

\begin{tabular}{lll}
\hline & Normal CVD & Bismuth immersed CVD \\
\hline Gas flow rate (sccm) & & \\
$\mathrm{H}_{2}$ & 80 & 80 \\
$\mathrm{CH}_{4}$ & 1 & 1 \\
$\mathrm{Ar}$ & 80 & 80 \\
substrate temperature $\left({ }^{\circ} \mathrm{C}\right)$ & 1000 & $900 \sim 1000$ \\
Pressure (Pa) & $6.5 \times 10^{3}$ & $6.5 \times 10^{3}$ \\
Bias voltage $(\mathrm{V})$ & - & $*$ \\
Distance between the substrate & - & $4 \sim 7$ \\
$\quad$ and the tip of rod (mm) & & \\
Duration (hour) & 24 & 24 \\
\hline
\end{tabular}

Table 2. The samples

\begin{tabular}{|c|c|c|c|c|}
\hline sample & Bias voltage $(\mathrm{V})$ & Substrate & Source gasses & nucleation \\
\hline (a) & 0 & $\mathrm{Si}$ & $\mathrm{CH}_{4}, \mathrm{H}_{2}, \mathrm{Ar}$ & Powder treatment \\
\hline (b) & +200 & $\mathrm{Si}$ & $\mathrm{CH}_{4}, \mathrm{H}_{2}, \mathrm{Ar}$ & Powder treatment \\
\hline (c) & -200 & $\mathrm{Si}$ & $\mathrm{CH}_{4}, \mathrm{H}_{2}, \mathrm{Ar}$ & Powder treatment \\
\hline (d) & $-200 /+200$ & $\mathrm{Si}$ & $\mathrm{CH}_{4}, \mathrm{H}_{2}, \mathrm{Ar}$ & Powder treatment \\
\hline (d') & $-200 /+200$ & Single crystal diamond & $\mathrm{CH}_{4}, \mathrm{H}_{2}, \mathrm{Ar}$ & $-\left(\mathrm{H}_{2}\right.$ plasma cleaning $)$ \\
\hline$(d ")$ & $-200 /+200$ & Single crystal diamond & $\mathrm{CH}_{4}, \mathrm{H}_{2}, \mathrm{Ar}$ & $-\left(\mathrm{H}_{2}\right.$ plasma cleaning $)$ \\
\hline$(d-i)$ & $-200 /+200$ & Mo mesh & $\mathrm{CH}_{4}, \mathrm{H}_{2}, \mathrm{Ar}$ & $\mathrm{BEN}$ \\
\hline (d-ii) & $-200 /+200$ & Mo mesh & $\mathrm{CH}_{4}, \mathrm{H}_{2}, \mathrm{Ar}$ & - \\
\hline (d-iii) & $-200 /+200$ & Mo mesh & $\mathrm{H}_{2}, \mathrm{Ar}$ & - \\
\hline
\end{tabular}

We prepared three types of samples with different growth conditions for the TEM analysis. The sample $(d-i)$ was pre-treated for nucleation by the BEN method and grown in the mixture gas containing $\mathrm{CH}_{4}, \mathrm{H}_{2}$, Ar, just as for the Si and diamond substrates. The sample (d-ii) was not treated for nucleation and grown in the mixture gas containing $\mathrm{CH}_{4}, \mathrm{H}_{2}$ and $\mathrm{Ar}$. The sample (d-iii) was not treated for nucleation and grown in the mixture gas only containing $\mathrm{H}_{2}$ and $\mathrm{Ar}$.

\subsection{Characterization}

The concentration of bismuth in the samples was studied by X-ray fluorescence (JEOL JSX-3100R II, 
$50 \mathrm{kV}$ ). The surface morphology was studied by laser microscopy (KEYENCE VK-8710). The crystal structure was characterized by XRD (Rigaku RINT-2000). The local structure was analysed by Raman microscopy (Renishaw inVia Raman microscope, $5 \mu \mathrm{m}$ spot size, $785 \mathrm{~nm}$ excitation). This $785 \mathrm{~nm}$ excitation is appropriate to observe graphite species including diamond and impurities [23]. The nanoscale structure and composition were examined by TEM with EDS (JEOL JEM-2010). The in-plane distribution and depth profile of Bi was analysed using an isotope microscope [24].

\section{Results and Discussion}

Figures 2 (a) (c) show the result of XRF data results for the growth conditions (a) (c) in Table 2. Bismuth was detected only from sample (c). It is thus considered that the negative bias voltage promotes the inclusion of the bismuth into the diamond films.

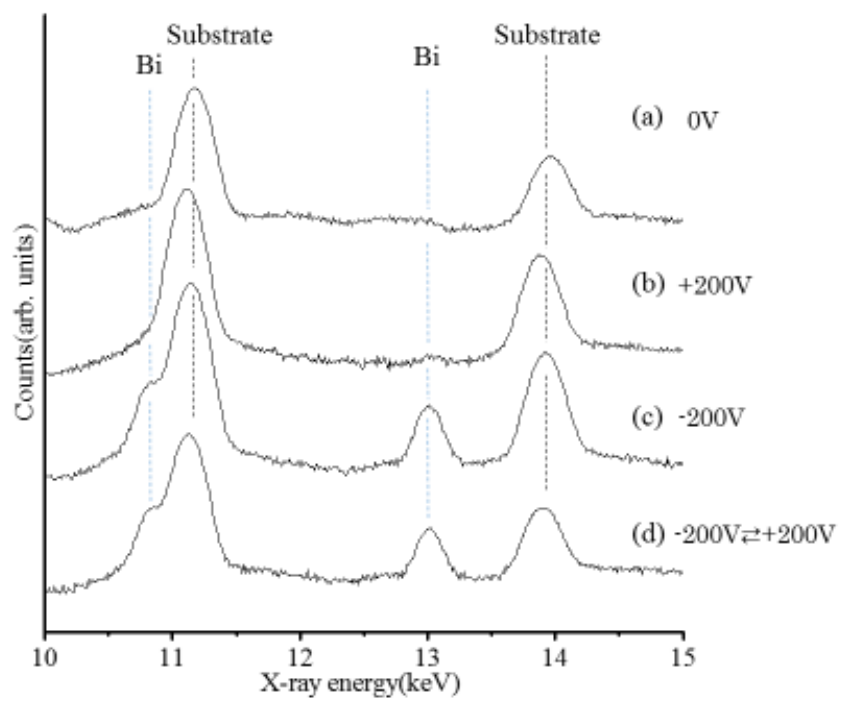

Fig.2. The results of XRF. (a)-(d) correspond to the growth conditions in Table 2.

Figures 3 (a) (c) show the corresponding XRD data. Sample (a) contained graphite, SiC and diamond. Sample (b) contained diamond and SiC only. Generally, SiC was observed as a by-product from the CVD diamond films on Si.[25] However, sample (c) was composed of diamond with a graphitic impurity. Therefore, we attempted a new pattern of applying bias to the substrate. For the new condition (d), the polarity of the bias was alternatingly switched every 30s. As a result, bismuth was also detected in sample (d) (Fig.2 (d)). As for the graphitic impurity detected by XRD, the ratio of graphitic/diamond species in sample (d) was about 1 / 5 of sample (c). The depth profile of bismuth in sample (d), possibly caused by alternating the bias voltage, will be discussed later.

The laser microscopy data of Fig. 4 (a) shows the surface morphology of the bismuth-immersed sample grown on the single- crystal diamond substrate by an alternating bias (sample (d') in Table 2). The surface of the sample was rough with non-epitaxial grains. In contrast, epitaxial grains were 
observed in Fig. 4(b) that shows the sample growth without immersing bismuth in the plasma (sample (d") in Table 2). It indicated that immersing bismuth enhances the abnormal grain growth.

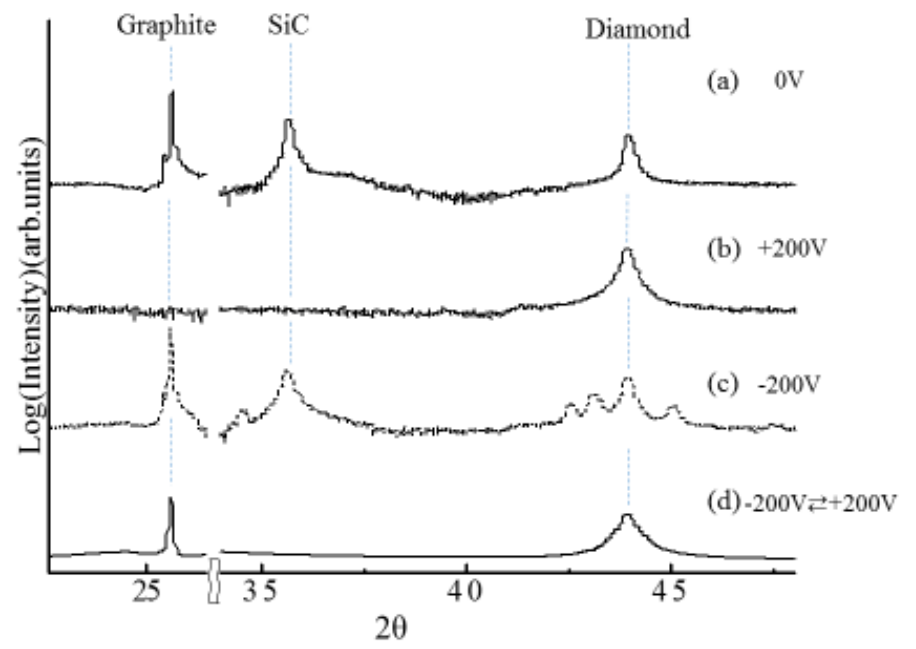

Fig.3. The results of XRD. (a)-(d) correspond to the growth conditions in Table 2. Strong signals from the substrates are observed in the region between $2 \theta=27-34^{\circ}$.
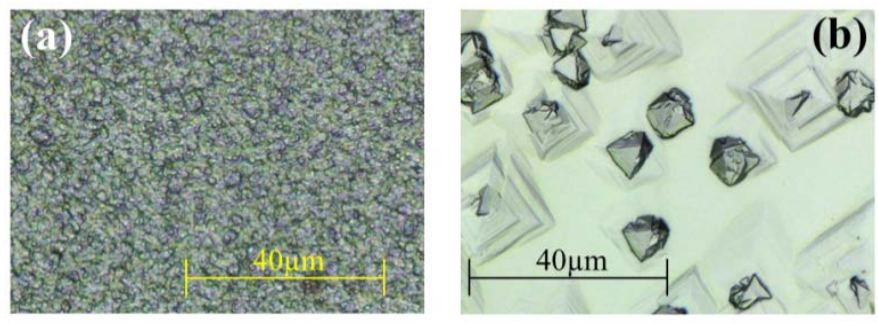

Fig.4. The surface morphology of the sample grown on the single crystal diamond substrate with alternating bias. (a) with bismuth immersion. (b) without bismuth immersion.

Generally, applying a positive bias to the substrate is used for enhancing the growth of the diamond, because the positive bias enhances the reactivity of the hydrogen radical on the surface of the substrate and increases the etching rate of the graphitic species [26]. On the other hand, applying a negative bias to the substrate increases the frequency of the ion bombardment. The ion bombardment causes etching of the diamond and accelerates the synthesis of $\mathrm{sp}^{2}$ carbon species (i.e., graphite). It results in graphitic impurities in the sample remaining without being etched. However, the result of samples (d) and (d') (the sample using the diamond substrate) indicated that applying an alternating bias is effective to decrease the amount of graphitic impurities and incorporating bismuth into the film.

Figure 5 shows the results of the Raman microscopy. Spectra taken from the sample grown with bismuth showed several different shapes depending on the position of the sample. The spectrum taken from the area of the flat crystal surface (Fig.5 (a)) had a smooth shape with a diamond peak $\left(1332 \mathrm{~cm}^{-1}\right)$. The poor crystallinity of the diamond seen from the broad background is probably due to the supply of 
Ar gas in the plasma, which will be discussed later. On the other hand, the spectrum taken from the area containing grain boundaries shows many peaks (Fig.5 (b)). It indicates the existence of a molecule-like carbon species or bismuth-carbon compounds at the grain boundaries. An example of a molecule-like carbon species is a diamondoid, i.e., a molecule composed of carbon with the $\mathrm{sp}^{3}$ structure $\left(\mathrm{C}_{4 \mathrm{n}+6} \mathrm{H}_{4 \mathrm{n}+12}, \mathrm{n}=1 \sim 5\right)$, which shows Raman spectra with many peaks[27-29]. Another possibility is $\mathrm{Bi}$ and $\mathrm{C}$ cluster molecules. Although there are no reports on the crystalline compounds of $\mathrm{Bi}$ and $\mathrm{C}$ to the authors' knowledge, there are some reports on cluster molecules made of bismuth and carbon.[30-32] Raman measurements of them have not been made.

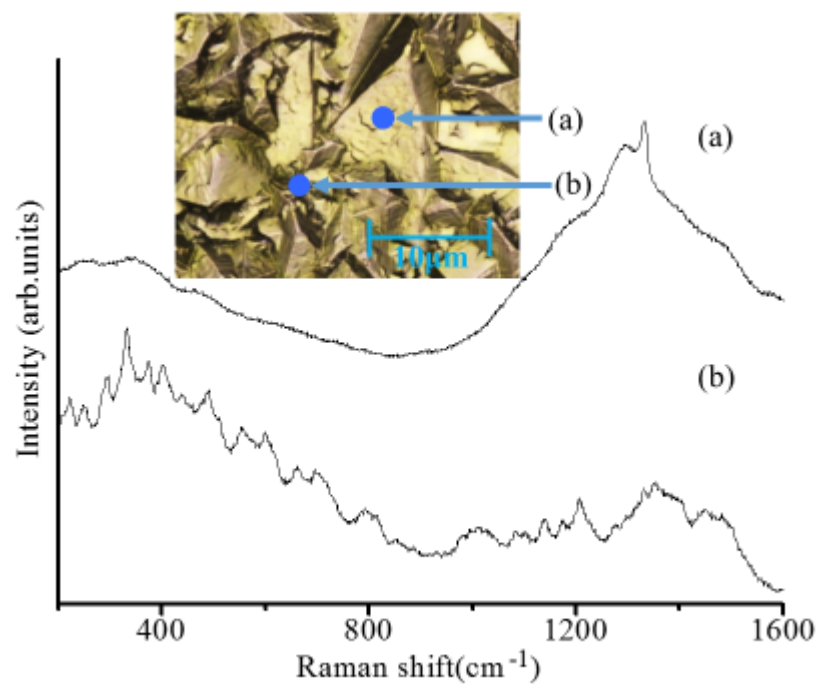

Fig.5. Raman spectra. (a) the area of the flat crystal surface. (b) the area containing grain boundaries. (inset) The sampled area of bismuth doped sample by laser Raman microscope. (diameter of laser spot is about $2 \mu \mathrm{m}$ )

(a)

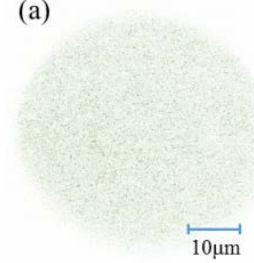

Carbon (b)

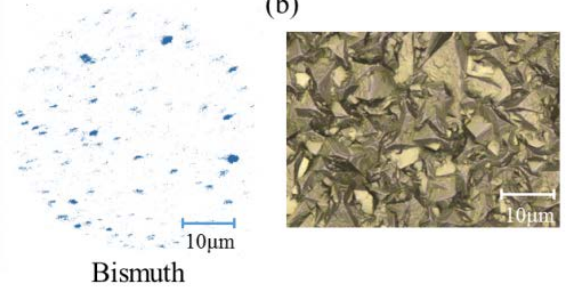

Fig.6. (a) The distributions of carbon and bismuth on the surface of the sample by using an isotope microscope. (b) The surface morphology of this sample by using a laser microscope.

The distribution of $\mathrm{Bi}$ in the sample was characterized by an isotope microscope (Fig.6 (a)). Carbon was uniformly distributed, while Bi was observed as spots. The distribution of Bi was similar to that of the grain boundaries (Fig.6 (b)). This indicates that the Bi had condensed between the grains of the diamond. The depth profile of bismuth was obtained by continuous SIMS-type operation of the 
isotope microscope. We carefully examined any periodicity in the depth profile, but the intensity of bismuth was constant. It suggests that the effect of the alternating bias was concentrated in each grain boundary, not forming layers in the film. It is reasonable if we assume that the period of the alternating bias was shorter than the growth time of each crystalline grain.

Figure 7 shows the results of the TEM analysis. From samples (d-i), we observed two kinds of structures, i.e., large grains (Fig.7 (a)) and nanoparticle aggregates (Fig.7 (b)). The diameter of the large grains and nanoparticles were $200 \mathrm{~nm}$ and $5 \sim 10 \mathrm{~nm}$, respectively. It seems that the nanoparticles are covered with a thin wrapping (Fig.7(b) inset). The large grains were identified as diamond from the selected area electronic diffraction (SAED). The region of the nanoparticle aggregates showed SAED with rings and spots with a strong halo. The lattice constants estimated from some of the rings and spots agreed with those of an unusual allotrope of carbon that is called Chaoite. Chaoite was first reported in meteorites[1,2], and it was also found as one of the byproducts during diamond plasma CVD at the very early stages[33], laser photochemical etching[34], carbon liquid quenching[35], and electrochemical processes[36]. Although the structure of Chaoite has not been elucidated in detail, it is considered to contain a carbyne structure[1,2], which can be very hard.[3]

(a)
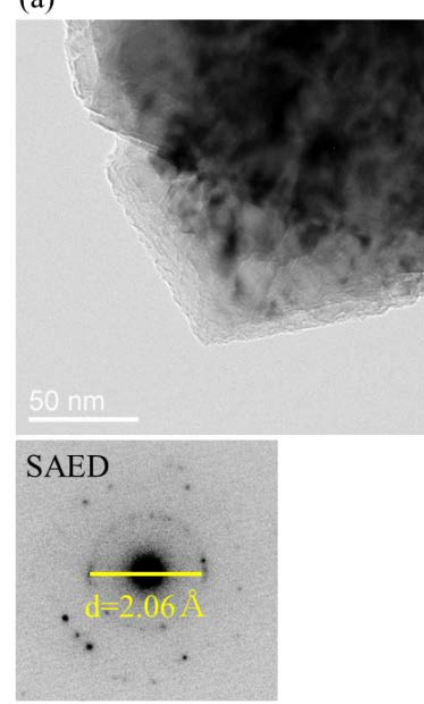

(b)
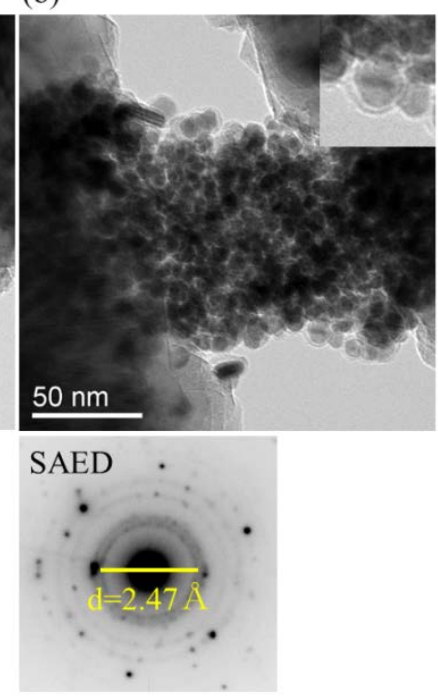

Fig.7. The results of the TEM analysis (a) Large grains. (b) Nanoparticle aggregates.

We observed bismuth from the EDS with the concentration of $85 \pm 0.5 \%$ in the area of nanoparticle aggregates. The area ratio of the core and shell, and the strong contrast in the core, strongly suggests that the core is made of bismuth and the shell is made of carbon. It should be noted that the nanostructures were only observed when diamond growth occurred with bismuth immersion. The sample (d-ii) grown without the nucleation procedure did not contain nanoparticles. The sample (d-iii), which was formed by depositing Bi only, showed nothing on the Mo mesh. This indicates that large grains and nanoparticle aggregates were synthesized only in the condition with both the $\mathrm{CH}_{4}$ and $\mathrm{BEN}$ 
processes. The source gas including Ar is not commonly used for the diamond thin film growth but used to synthesize a ultra-nano-crystalline diamond film[37]. When we used $\mathrm{H}_{2}+\mathrm{CH}_{4}$ gas without Ar gas, the amount of synthesized nanoparticle-aggregates were supressed and the concentration of bismuth was low. In our growth conditions, the gas consisted of $\mathrm{H}_{2}: \mathrm{Ar}=1: 1$ yieled poly-crystalline diamond and the nanoparticle aggregates at grain boundaries.

Figure 8 shows the presumed structure of a diamond film grown and Bi immersion with alternating bias. The sample is mainly composed of polycrystalline diamond. There are nanoparticle aggregates at the grain boundary where $\mathrm{Bi}$ was only detected. The nanoparticles have core-shell structures. The shell probably contains molecule-like species such as diamondoids and bismuth-carbon clusters, as observed by the Raman microscopy (Fig.5 (b)). The core is composed of bismuth. There are also crystals of the unusual carbon allotrope Chaoite in this region.

Since Bi-containing compounds show various useful functions such as photocatalysis[38-40] and multiferroics[41] partly in relation to the lone pair in the valence shell of $\mathrm{Bi}$, the $\mathrm{Bi}$ - $\mathrm{C}$ nanocomposite reported here may add a new variation in the functional Bi compounds and composites[42].

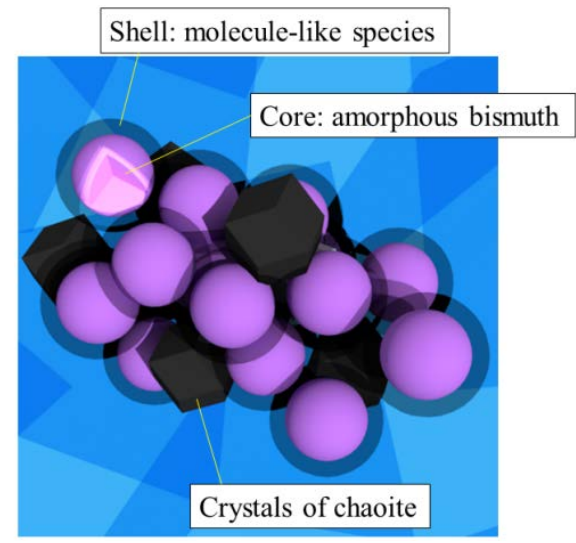

Fig.8. Presumed structure of the nanoparticle aggregates.

\section{Conclusions}

We investigated the possible doping of bismuth in diamond by immersing bismuth in the plasma during the CVD growth of diamond. The resulting film was polycrystalline diamond showing an abnormal nucleation. The main portion of bismuth in the film was not in the diamond lattice, but it was included in the core of the aggregated nanoparticles at the grain boundaries. The shell of the nanoparticles contains molecule-like species such as diamondoids or Bismuth-carbon clusters. We also detected the unusual carbon allotrope Chaoite near the grain boundary.

\section{Acknowledgements}


TEM analysis was supported by Nanotechonology platform at Hokkaido University by METI, Japan. The analysis of element distribution in the film was carried out with Isotope Microscope at Isotope Imaging Laboratory, Hokkaido University. TY is grateful for the support from Frontier Chemistry Center, Faculty of Engineering, Hokkaido University.

Valuable discussion with and support from Prof. T. Hasegawa (The University of Tokyo) and his group members through CREST program is acknowledged.

\section{References}

1. A.G. Whittaker, P.L. Kintner, Carbon: Observations on the New Allotropic Form, Science, 165 (1969) 589-591.

2. P.P. Smith, P.R. Buseck, Carbyne forms of carbon: do they exist?, Science. 216 (1982) 984-986.

3. M. Liu, V. I. Artyukhov, H. Lee, F. Xu, and B.I. Yakobson,Carbyne from first principles: Chain of c atoms, a nanorod or a nanorope, ACS Nano, 2013, 7, 10075-10082.

4. W. L Mao, H.-K. Mao, P.J. Eng, T.P. Trainor, M. Newville, C-C. Kao, D. L. Heintz, J. Shu, Y Meng, R.J. Hemley, Bonding Changes in Compressed Superhard Graphite, Science. 302 (2003) 425-427.

5. Q. Li, Y. Ma, A.R. Oganov, H. Wang, H. Wang, Y. Xu, T. Cui, H.K. Mao, G. Zou, Superhard monoclinic polymorph of carbon, Phys. Rev. Lett. 102 (2009) 175506.

6. K. Umemoto, R.M. Wentzcovitch, S. Saito, T. Miyake, Body-centered tetragonal $\mathrm{C}_{4}$ : A viable $\mathrm{sp}^{3}$ carbon allotrope, Phys. Rev. Lett. 104 (2010) 125504.

7. M. Amsler, J.A. Flores-Livas, L. Lehtovaara, F. Balima, S.A. Ghasemi, D. MacHon, S. Pailhès, A. Willand, D. Caliste, S. Botti, A. San Miguel, S. Goedecker, M.A.L. Marques, Crystal structure of cold compressed graphite, Phys. Rev. Lett. 108 (2012) 065501.

8. A. Hiraiwa, H. Kawarada, Figure of merit of diamond power devices based on accurately estimated impact ionization processes, J. Appl. Phys. 114 (2013) 034506.

9. I. Aharonovich, A.D. Greentree, S. Prawer, Diamond Photonics, Nat. Photonics. 5 (2011) 397-405.

10. M.S. Grinolds, M. Warner, K. De Greve, Y. Dovzhenko, L. Thiel, R.L. Walsworth, S. Hong, P. Maletinsky, A. Yacoby, Subnanometre resolution in three-dimensional magnetic resonance imaging of individual dark spins, Nat. Nanotechnol. 9 (2014) 279-284.

11. T. Iwasaki, F. Ishibashi, Y. Miyamoto, Y. Doi, S. Kobayashi, T. Miyazaki, K. Tehra, K.D. Jahnke, L.J. Rogers, B. Naydenzov, F. Jelezko, S. Yamasaki, S. Nagamachi, T. Inubushi, N. Mizuochi, M. Hatano, Germanium-Vacancy Single Color Centers in Diamond, Scientific Reports, 5 (2015) 12882.

12. J.D. Hunn, N.R. Parikh, M.L. Swanson, R.A. Zuhr, Conduction in ion-implanted single-crystal diamond, Diam. Relat. Mater. 2 (1993) 847-851.

13. J.L. DiMeglio, J. Rosenthal, Selective conversion of $\mathrm{CO}_{2}$ to $\mathrm{CO}$ with high efficiency using an inexpensive bismuth-based electrocatalyst, J. Am. Chem. Soc. 135 (2013) 8798-7801.

14. K.E. Toghill, G.G. Wildgoose, A. Moshar, C. Mulcahy, R.G. Compton, Fabrication and characterization of a bismuth nanoparticle modified boron doped diamond electrode and its application 
to the simultaneous determination of cadmium(II)and lead(II), Electroanalysis. 20 (2008) 1731-1737. 15. K. Nakata, T. Ozaki, C. Terashima, A. Fujishima, Y. Einaga, High-Yield Electrochemical Production of Formaldehyde from $\mathrm{CO}_{2}$ and Seawater, Angew. Chemie Int. Ed. 53 (2014) 871-874.

16. P.N. Volpe, J.C. Arnault, N. Tranchant, G. Chicot, J. Pernot, F. Jomard, P. Bergonzo, Boron incorporation issues in diamond when TMB is used as precursor: Toward extreme doping levels, Diam. Relat. Mater. 22 (2012) 136-141.

17. J.F. Prins, Bipolar transistor action in ion implanted diamond, Appl. Phys. Lett. 41 (1982) 950-952. 18. T. Tamura, T. Yanase, T. Nagahama, M. Wakeshima, Y. Hinatsu, T. Shimada, Versatile Simple Doping Technique for Diamond by Solid Dopant Source Immersion during Microwave Plasma CVD, Chem. Lett. 43 (2014) 1569-1571.

19. A.V. M. Kunze G. Dollinger , A. Bergmaier , E. Kohn, Delta-Doping To Diamond, Carbon, 37 (1999) 787-791.

20. S. Yugo, T. Kanai, T. Kimura, T. Muto, Generation of diamond nuclei by electric field in plasma chemical vapor deposition, Appl. Phys. Lett. 58 (1991) 1036-1038.

21. J. Nakata, Y. Hoshino, Y. Saito and K. Kawasaki, Research for Electrical Activation of Ion-implanted Diamond Semiconductors. Using MeV Ion Beam Irradiation - Research for Formation of High-Quality Diamond Epitaxial Thin Layers on the Diamond Substrates and Evaluation of These Layers -, Scientific Journal of Kanagawa University, 20 (2009) 17-38.

22. NIST Atomic Spectra Database, http://www.nist.gov/pml/data/asd.cfm 2016 (accessed 16.06.16).

23. A.C. Ferrari, Diam. Relat. Mater. 11 (2002) 1053-1061.

24. H. Yurimoto, K. Nagashima, T. Kunihiro, High precision isotope micro-imaging of materials, Appl. Surf. Sci. 203-204 (2003) 793-797.

25. B.E. Williams, J.T. Glass, Characterization of Diamond Thin-Films - Diamond Phase Identification, Surface-Morphology, and Defect Structures, J. Mater. Res. 4 (1989) 373-384.

26. D. Saito, H. Isshiki, T. Kimura, Positive-bias enhanced growth of high quality diamond films by microwave plasma chemical vapor deposition, Diam. Relat. Mater. 18 (2009) 56-60.

27. J. Filik, J.N. Harvey, N.L. Allan, P.W. May, J.E.P. Dahl, S. Liu, R.M.K. Carlson, Raman spectroscopy of diamondoids, Spectrochim. Acta. A. Mol. Biomol. Spectrosc. 64 (2006) 681-692.

28. P.W. May, J. a. Smith, K.N. Rosser, $785 \mathrm{~nm}$ Raman spectroscopy of CVD diamond films, Diam. Relat. Mater. 17 (2008) 199-203.

29. J. Filik, J.N. Harvey, N.L. Allan, P.W. May, J.E.P. Dahl, S. Liu, R.M.K. Carlson, Raman spectroscopy of nanocrystalline diamond: An ab initio approach, Phys. Rev. B. 74 (2006) 035423.

30. J.E. Reddic, M. a. Duncan, Composite samples and the generation of novel metal carbide clusters, Chem. Phys. Lett. 264 (1997) 157-162.

31. Y. Yamada, T. Nakagawa, Bismuth carbide cluster ions produced by a gas aggregation source, Int. J. Mass Spectrom. 282 (2009) 123-127.

32 L. Gao, P. Li, H. Lu, S.F. Li, Z.X. Guo, Size- and charge-dependent geometric and electronic structures of Bin (Bin-) clusters ( $\mathrm{n}=2-13)$ by first-principles simulations, J. Chem. Phys. 128 (2008), 194304. 
33 W. Yarbrough, R. Messier, Current Isssues and Problems in the Chemical Vapor Deposition of Diamond, Science, 247 (1990) 688-696.

34 J. Pola, A. Ouchi, S. Bakardjieva, V. Vorlicek, M. Marysko, J. Subrt, Z. Bastl, Laser photochemical etching of silica: Nanodomains of crystalline chaoite and silica in amorphous C/Si/O/N phase, J. Phys. Chem. C. 112 (2008) 13281-13286.

35 A.Y. Basharin, V.S. Dozhdikov, V.T. Dubinchuk, A. V. Kirillin, I.Y. Lysenko, M.A. Turchaninov, Phases formed during rapid quenching of liquid carbon, Tech. Phys. Lett. 35 (2009) 428-431.

36 C. Pang, N. Li, C.X. Wang, Intercalated $\mathrm{SiO}_{2}$ \& Si/Carbon Composite for High Capacity Li Ion Battery Anodes, Electrochim. Acta. 141 (2014) 226-233.

37. D. M. Gruen, Solid State NMR study of nanodiamond surface chemistry, Annu. Rev. Mater. Sci. 29 (1999) 211-259.

38 A. Kudo, K. Omori, H. Kato, JA novel aqueous process for preparation of crystal form-controlled and highly crystalline $\mathrm{BiVO}_{4}$ powder from layered vanadates at room temperature and its photocatalytic and photophysical properties, . Am. Chem. Soc. 121 (1999) 11459-11467.

39 M. Shang, W. Wang, S. Sun, L. Zhou, L. Zhang, $\mathrm{Bi}_{2} \mathrm{WO}_{6}$ Nanocrystals with High Photocatalytic Activities under Visible Light, J. Phys. Chem. C. 112 (2008) 10407-10411.

40. M. Guan, C. Xiao, J. Zhang, S. Fan, R. An, Q. Cheng, Vacancy Associates Promoting Solar-Driven Photocatalytic Activity of Ultrathin Bismuth Oxychloride Nanosheets, J. Am. Chem. Soc. 135 (2013) 10411-10417.

41 N.A. Hill, Why Are There so Few Magnetic Ferroelectrics?, J. Phys. Chem. B. (2000) 6694-6709.

42 G.-H. Hwang, S.-J. Hong, W.-K. Han, J.-S. Park, S.-G. Kang, Bismuth/Glassy Carbon Composite Electrode for the Determination of Trace Lead and Cadmium, ECS Trans. 16 (2008) 557-565. 